\title{
On farm demonstration of improved lettuce variety (Lactuca Sativa) in Southeastern zone of Tigray, Ethiopia
}

\author{
Luchia Tekle*, Niguse Abebe and Mehari Asfaw \\ Mekelle Agricultural Research Center, Tigray Agricultural Research Institute, P. O. Box 258, Mekelle, Ethiopia.
}

Received 14 March, 2018; Accepted 14 May, 2018

\begin{abstract}
Improved slow bolting lettuce variety is one of the important traits of lettuce for farmers in the study area to increase their production and income. Therefore a field experiment was conducted in Enderta district of South eastern zone of Tigray with the objective to evaluate and demonstrate the slow bolting lettuce variety, enhance the income of farmers by increasing production and productivity, and participate in farmers' research group in evaluation and demonstration of varieties. Improved (Tesfa Mekelle) and local (Paris Island) lettuce varieties were used as treatment for demonstration. 20 farmers were selected which have access to irrigation and willingness to participate. Both qualitative and quantitative data were collected. To measure the attitude of farmers towards improved technology, a five-point Likert scale method was used. The data was analyzed using appropriate software. To calculate the gap analysis, technology gap and technology index were used. The results revealed that farmers obtained an average of $\mathbf{4 1 2 . 8 9}$ and $283.83 \mathrm{qt} \mathrm{ha}^{-1}$ biomass yield of lettuce from improved and local varieties, respectively. This can clearly show that farmers can increase their lettuce yield and income by $\mathbf{4 5 . 5}$ and $\mathbf{7 9 . 5 \%}$ using the improved variety, respectively. Based on the farmers' perception, the study also showed that farmers were satisfied in all parameters of improved lettuce like adaptability, slow bolting, marketability, tasty, softness of leaves and productivity. Therefore, research center and the offices of agriculture and rural development of the respective districts should take the lead to further popularization of the variety for their respective mandate areas to boost production and productivity of lettuce.
\end{abstract}

Key words: On farm demonstration, improved lettuce, yield, farmers' perception.

\section{INTRODUCTION}

Lettuce (Lactuca sativa L.) an annual leafy herb belongs to the family compositae is one of the most popular salad crops and occupies the largest production area among salad crops in the world. It is popular for its delicate,

${ }^{*}$ Corresponding author. E-mail: tek2luch@gmail.com.

Author(s) agree that this article remain permanently open access under the terms of the Creative Commons Attribution 
crispy texture and slightly bitter taste with milky juice as fresh condition. It is the most popular amongst the salad vegetable crops (Squire et al, 1987). Lettuce is one of the most important vegetable crops in temperate regions (Lebeda et al., 2007).

Lettuce is produced commercially in many countries and is also widely grown as a vegetable in home gardens (Kristkova et al., 2008). It is extremely sensitive to drought due to shallow root system. Lettuce can grow in a variety of soil types and climatic conditions. Lettuce, in general, is a crop with distinct temperature requirements. Optimal growing temperatures range between $23^{\circ} \mathrm{C}$ during the day and $7^{\circ} \mathrm{C}$ at night. It grows within an altitude of 18002100 m.a.s.l. It is best grown in silt loams and sandy soils as these soil types provide better drainage and warm up more readily during the day, which is especially important during cooler periods of the growing season (Kristkova et al., 2008). There are a range of lettuce varieties available allowing gardeners to select those that are easy to grow, highly productive in limited space, and virtually pest and disease free. Lettuce is definitely one of the more "care-free" crops (Kiros et al., 2012). Lettuce is usually used as salad with tomato, carrot, cucumber or other salad vegetable and often served alone or with dressing. Likewise, in Tigray, Lettuce is an important cash and food security crop for small holder farmers and fresh salad retailers (Beyenesh et al., 2017).

Lettuce cultivation is common in many parts of Tigray, Ethiopia. The demand for lettuce production and consumption has increased; few varieties are available with only 'Paris Island' widely grown by farmers. This variety is an erect type and low in biomass yield. Moreover, early bolting is a major problem for the varieties being grown. Such varieties limit the time farmers have to harvest the crop to supply their production to the market on time. Thus, new lettuce varieties have been introduced and tested in different mandate areas. One promising variety, Tesfa Mekelle, showed slow-bolting and greater adaptability. However, demonstration of this lettuce variety in farmers' fields was not done widely in order to promote this variety in other areas. It is also vital to demonstrate this slow-bolting variety in comparison with local lettuce variety under farmer's condition. Therefore, this study was initiated with the objective of demonstrate the improved slow bolting lettuce variety on production, productivity with the local variety.

\section{MATERIALS AND METHODS}

\section{Description of the study area}

The experiment was conducted at Enderta which is one of the six districts in the Southeastern administrative zone of Tigray (Figure 1). It is geographically located at a longitude of $13^{\circ}: 15^{\prime}: 00^{\prime \prime} \mathrm{N}$ and a latitude of $39^{\circ}: 30^{\prime}: 30^{\prime \prime} \mathrm{E}$ with an altitude ranging from 1500 to 2300 m.a.s.I. It shares borders with Kilte awlaelo district in the north,
Hintalo Wajirat in the south, Afar regional state in the east and the district of Degu'a Tembien in the west (Almaz, 2008). The district covers a total area of $89,812 \mathrm{~km}^{2}$ of which 30,062 hectares are agricultural land. The total population size is 129,886 (CSA, 2011). It constitutes 17 sub-districts and 67 villages. The capital city of the region, Mekelle, is encircled within Enderta making it more advantageous to the district from market proximity point of view. The agro-climatic is mainly (96\%) warm mild with the remaining 3 and $1 \%$ hot low land climate and temperate climate, respectively. Annual average rainfall ranges from 450 to $550 \mathrm{~mm}$. Smallholder mixed farming remains the single largest contributor to the livelihoods of the population. Major crops grown in the district include teff, wheat, barley, sorghum, millet, oil seeds, pulse seeds, horticultural crops including vegetables especially leaf vegetables (Figure 1).

\section{Sampling techniques and experimental design}

The demonstration was conducted in Enderta district tabia Arato under irrigation. Twenty farmers were selected based on their interest in the technology, access of irrigation, willingness to manage and allocate field trial for the activity with collaboration of extension agents. The lettuce varieties were sown in the nursery and the seedlings were transplanted at 5-6 leaf stage to wellprepared beds in the field. The improved lettuce variety called Tesfa Mekelle and the popular local variety Paris Island were planted in each farmer's field. Each variety was planted in $100 \mathrm{~m}^{2}$ demonstration plot in 20 farmers field and each farmer consider as replication. Rows were spaced at $60 \mathrm{~cm}$ and $40 \mathrm{~cm}$ spacing between plants. Date of planting was the same for both varieties. The experiment followed a mother trial approach in which researchers designed and farmers implemented (Witcombe et al., 2002). All necessary crop husbandry practices such as fertilization, weeding and hoeing were implemented as recommended. The field was irrigated every week to meet the water requirement of the crop.

\section{Data collection and analysis}

Biomass yield that was determined by Fresh Leaf Weight: The total fresh biomass yield from both cultivars was measured by uprooting them from the ground and removes the soil from the root part of plant loose soil and weigh immediately. The height of the main plant was determined by measuring from the border of the soil to the top of the main plant stem. Number of Leaf per Plant was determined by counting the healthy leaf by selecting ten plants randomly from each plot and Leaves diameter(width) was measured by selecting ten plants randomly from each plot by measuring the width at the middle part of the leaves (at widest part of the leaves).

Farmers' point of view on the attributes of Tesfa Mekelle based on the composite indicators of yield and yield components was collected using Likert scale method, a format that is preferred by Derrick and White (2017). Group discussion (2 groups) was undertaken to collect data on farmer's opinion on the variety. Checklists were used for interviewing the participants to assess their interest in the technology for promotion. Production costs and benefits were collected to see the profitability difference of the treatments.

After data collection, coding and entering the data into SPSS version 20.0 computer program were done for the analysis. Data (quantitative data) were analyzed using t-test and descriptive statistics such as mean, standard deviation, percentage and frequency distribution to compare mean of varieties while qualitative data were analyzed through qualitative interpretation and summarization. Gap analysis was conducted for technology gap, extension gap and technology index using the formulae of Samui 
Table 1. Biomass yield of improved lettuce variety Tesfa Mekelle and local variety Paris Island.

\begin{tabular}{lccccccc}
\hline \multirow{2}{*}{ Commodity } & \multicolumn{7}{c}{ Yield $\left(\mathbf{q t}\right.$ ha $^{-1}$ ) } \\
\cline { 2 - 9 } & Min & Max & Mean & Standard deviation & t & SEM $^{*}$ & P-value \\
\hline Tesfa Mekelle & 350 & 456.28 & 412.89 & 34.49 & 7.4 & 14.5 & \multirow{2}{*}{0.000} \\
Paris Island & 236.58 & 312.56 & 283.83 & 25.22 & 7.4 & 9.6 & \\
\hline
\end{tabular}

*SEM- standard error difference.

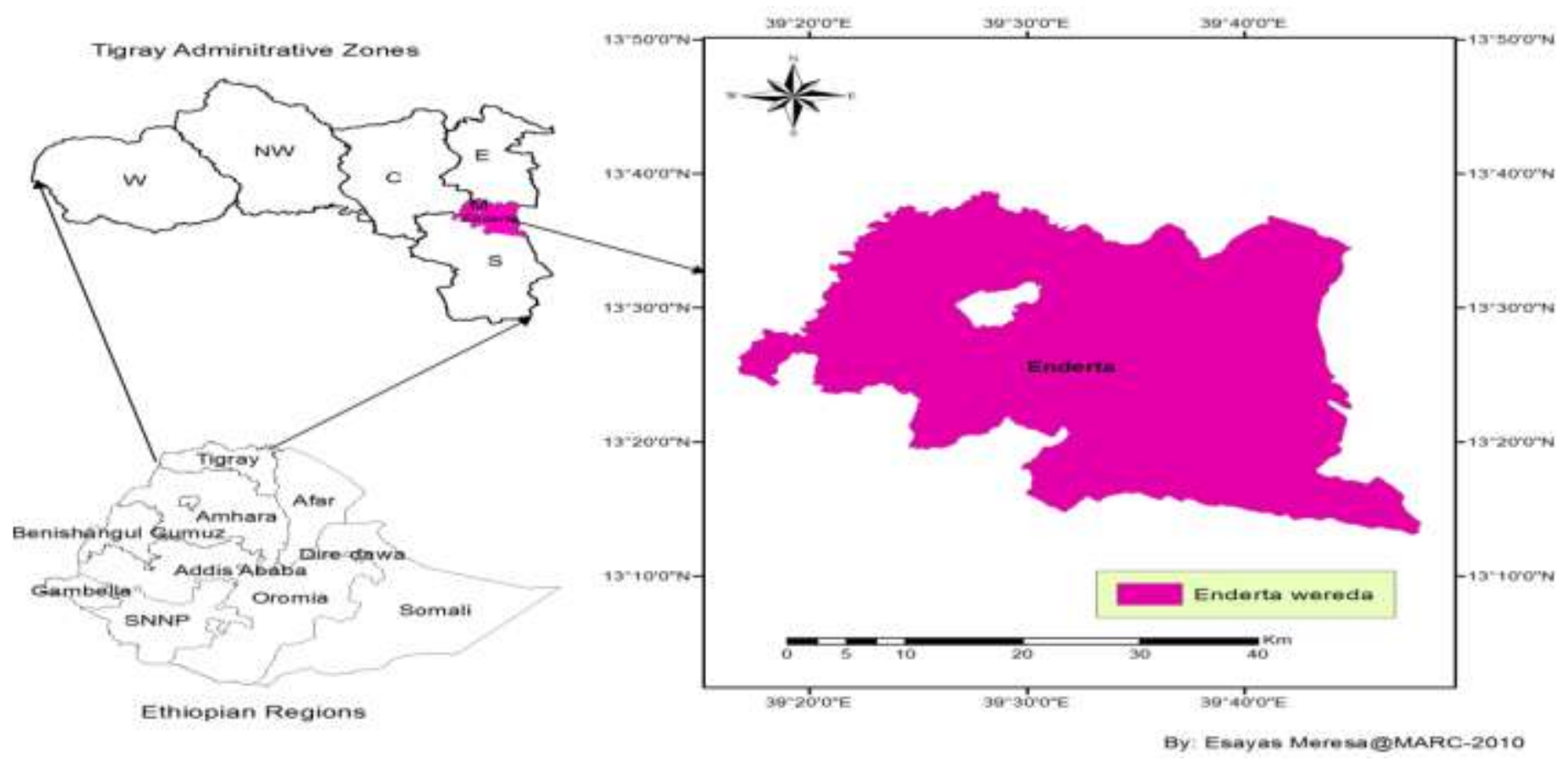

Figure 1. Map of the study area.

et al. (2000) as follows:

Technology gap $=$ Potential Yield - Demonstration Yield Extension gap $=$ Demonstration Yield - Yield under farmers practice Technology index $(\%)=(($ Potential Yield - Demonstration Yield $) /$ Potential Yield) $) \times 100$

\section{RESULTS AND DISCUSSION}

\section{Comparisons of biomass yield}

The improved variety Tesfa Mekelle showed higher biomass yield than local variety Paris Island at the 20 locations. Moreover, the minimum yield of Tesfa meklle variety was higher than maximum of local variety (Table 1). An independent sample t-test was conducted to compare the mean difference between improved variety and local with respect to biomass yield. The t-test result also showed that there is statistically significant mean difference between the two groups at less than $1 \%$ probability level $(t=7.4)$ (Table 1$)$. Similar yield enhancement in different crops in demonstration have been documented by Hiremath et al. (2009), Mishra et al. (2009), Kumar et al. (2010) and Dhaka et al. (2010). Soto-Cerda et al. (2014) revealed that one important way to increase agricultural productivity is through the introduction of improved agricultural technologies and management systems. This may lead to increase the production efficiency of crop commodity at smallholders' level that is an important step to attain food selfsufficiency for the country (Figure 1). The observed technology gap may be due dissimilarity in the soil fertility status, weather condition and other management practices (Mitra et al., 2010; Katare et al., 2011; Tiwari et al., 2013). Variety-wise location specific recommendation with full package of practices and other pre-requisite appears to be necessary to minimize the technology gap for yield level under different situations. Such steps would boost up the production and bring more prosperity to the farming community. The technology index shows that the feasibility of the evolved technology at the farmers' fields, 
Table 2. Yield, technology gap and technology index of demonstration.

\begin{tabular}{lcccc}
\hline Variety & Yield $\left(\mathbf{q t ~ h a ~}^{-1}\right.$ ) & Yield increment (\%) & Technology gap (qt ha ${ }^{-1}$ ) & Technology index\% \\
\hline Tesfa Mekelle & 412.89 & 45.5 & 87.11 & 17.4 \\
Paris Island & 283.83 & - & - & - \\
\hline
\end{tabular}

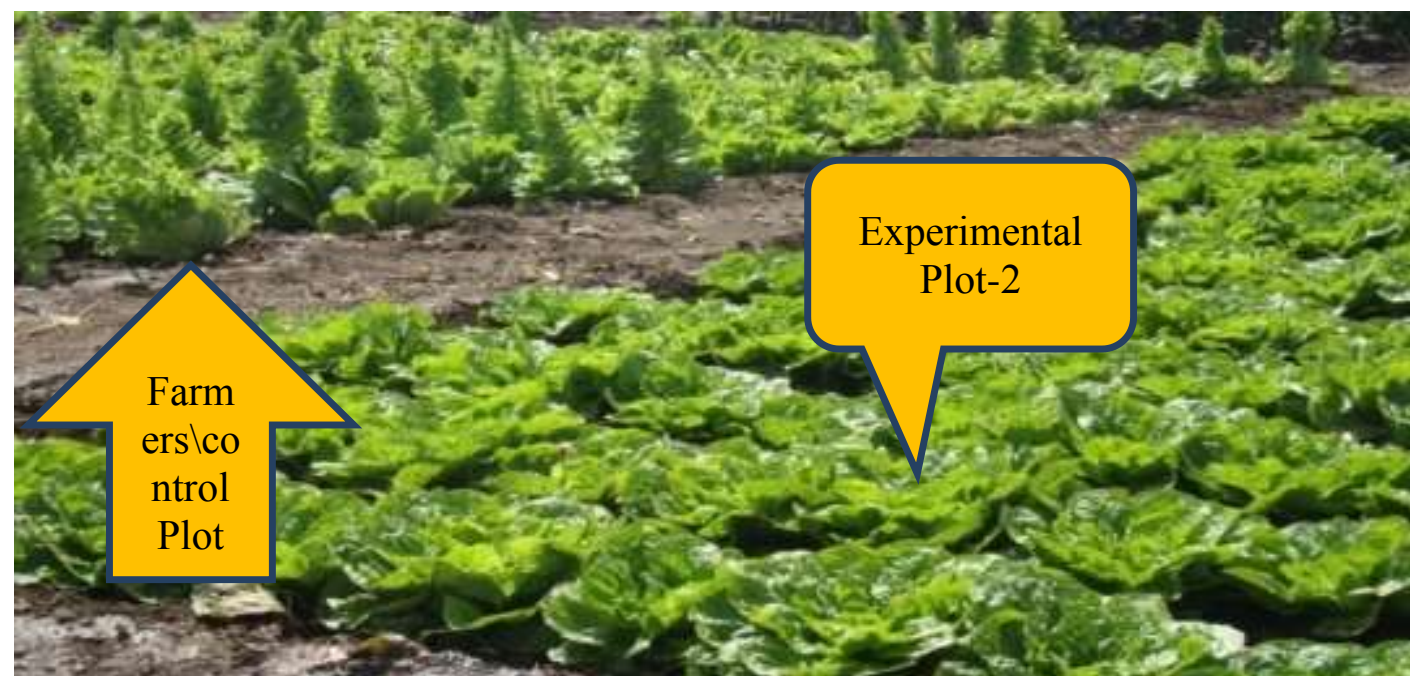

Figure 2. Illustration of demonstration plots showing bolting characteristics of the varieties

as lower the value of technology index more is the feasibility of the technology (Jeengar et al., 2006) (Table 2).

\section{Agronomic performance}

Tesfa Mekelle showed good performance for some agronomic parameters that contributed for biomass yield over Paris Island (Figure 2). The mean of stand count and leaf number of Tesfa Mekelle was 43 and 45.6 respectively which is higher than the local variety. While the average stands count and leaf number of Paris Island was 37 and 38.6 respectively. Moreover, the average plant height and leaf diameter of Tesfa Mekelle was $28 \mathrm{~cm}$ and $49.6 \mathrm{~cm}$. whereas Paris Island was 22 and 36 $\mathrm{cm}$. This indicates that Tesfa mekelle has a good Agronomic performance, these contributes to harvest more yield (Figure 3).

\section{Cost benefit analysis of improved lettuce verses local}

Data from cost benefit analysis were presented in Table 3. This implied that the net benefit gained from the improved lettuce variety is higher by $79.5 \%$ than that of the local cultivars. Therefore, higher productivity and profitability made improved lettuce production more competitive implying that the need for encouragement of improved variety in the study area from economic as well as food security perspective.

\section{Perception of farmers towards the improved versus local variety}

The percentage scores of farmers' response to the perception statements of each attributes that relate to perceived technological characteristics are given in the Table 4. In general, the host communities have positive perception on the below mentioned attributes of the variety.

\section{Focus group discussion result}

The farmers' feedbacks on the use of the improved variety are as follows.

(1) All farmers in the groups agreed that improved variety (Tesfa Mekelle) was really adaptable and real slow bolting

(2) They said that the improved variety highly preferable and tasty

(3) In comparison with local one the improved variety have high market quality demand which they maintain the 


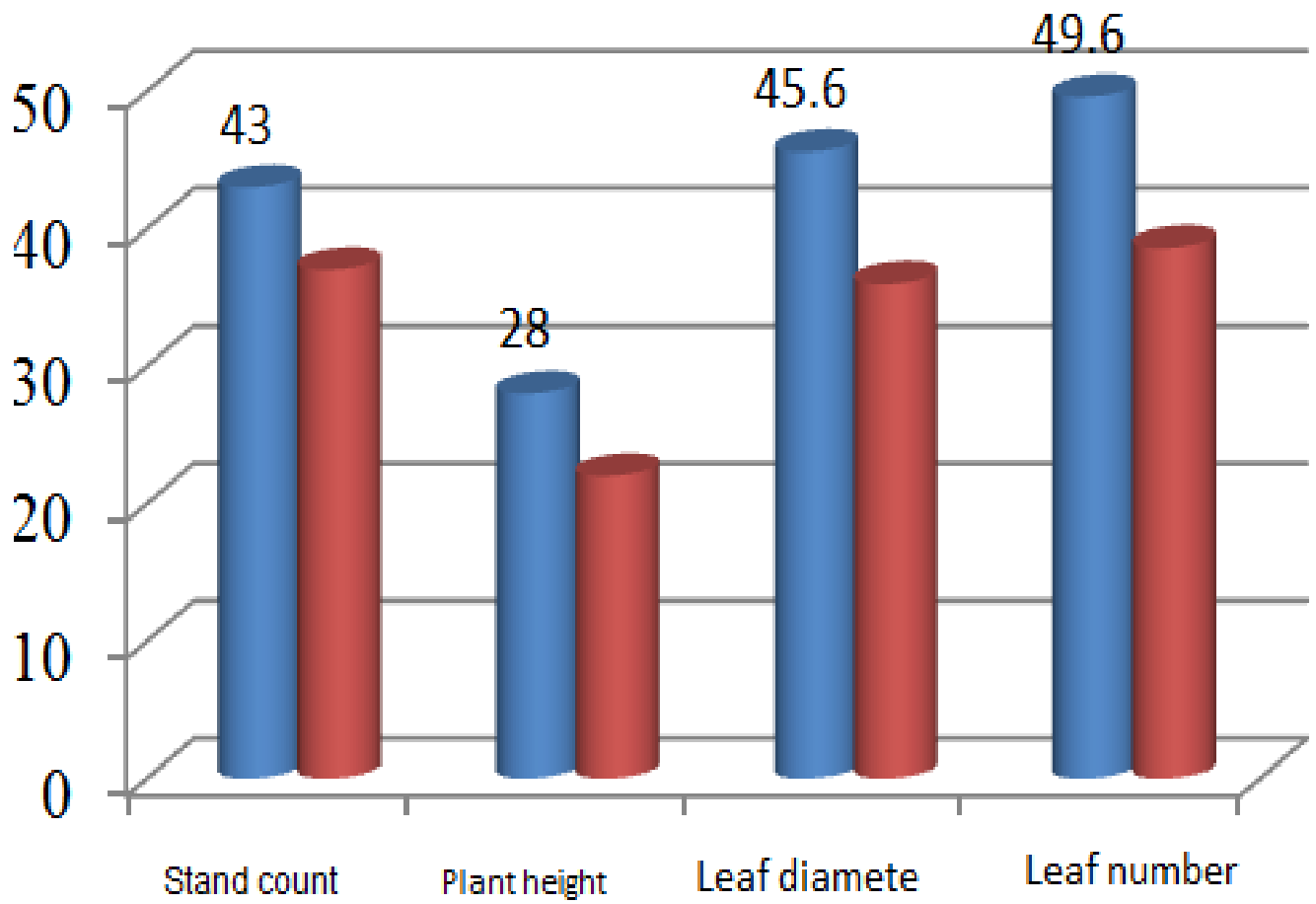

Improved

Figure 3. Aveage plant height, average leaf diameter (width), and leaf number.

Table 3. Cost benefit analysis and profitability of sample farmers (Birr ${ }^{1}$ per hectare).

\begin{tabular}{lccccc}
\hline Variety & Average cost of production (Birr) & Average qt produced & Average price/qt & Total revenue & Net revenue (Birr) \\
\hline Improved & 15000 & 412.89 & 650 & 268378.5 & 253378.5 \\
Local & 15000 & 283.83 & 550 & 156106.5 & 141106.5 \\
\hline
\end{tabular}

Table 4. Farmers' perceptions on characteristic of lettuce variety, $2014(\mathrm{~N}=20)$.

\begin{tabular}{lccccc}
\hline \multirow{2}{*}{ Attributes } & \multicolumn{5}{c}{ Perception level (\%) } \\
\cline { 2 - 6 } & Very poor & Poor & Neutral & Good & Very good \\
\hline Early maturity & - & - & - & - & 100 \\
Germination ability/growth habit & - & - & - & 25 & 75 \\
Bolting & - & - & - & - & 100 \\
Plant size & - & - & - & - & 100 \\
Leaf width & - & - & - & - & 100 \\
Plant height & - & - & - & - & 100 \\
Insect resistance & - & - & - & - & 100 \\
Disease resistance & - & - & - & - & 100 \\
Drought tolerance & - & - & - & - & 100 \\
Leaf no per plant & - & - & - & - & 100 \\
Length of maturity & - & - & - & - & 100 \\
softness of the leaf & - & - & - & - & 100 \\
Marketability & - & - & - & - & 100 \\
Taste & - & - & - & - & 100 \\
\hline
\end{tabular}

${ }^{1}$ Ethiopian Birr is equivalent of 0.0365 US Dollar (National Bank of Ethiopia accessed on March 25, 2018) 
color preference and plant size.

(4) The improved variety (Tesfa Mekelle) has soft leaves as compare with existing one.

\section{Conclusion}

The results of the present study revealed that improved Tesfa Mekelle lettuce variety had good acceptance by farmers with its quality, yield, late flowering or slow bolting and high market acceptability. It should be bear in mind that any technology or variety can perform as expected if and only if all the recommended management practices are properly applied. Therefore, the improved lettuce should be popularized to large areas and number of farmers of their respective mandate area to boost production and productivity of lettuce through the contribute to food security of farming households.

\section{CONFLICT OF INTERESTS}

The authors have not declared any conflict of interests.

\section{REFERENCES}

Almaz M (2008). Cooperative study on the performance of dairy cooperative input and out marketing in Astbie Womberta, Alamata, and Enderta Woreda in Tigray Region Ethiopia. Msc thesis Mekelle University.

Beyenesh Z, Niguse A, Mereseit H (2017). Effect of Inter and Intra-Row Spacing on Yield and Yield Components of Lettuce (Lactuca Sativa) in South East Tigray, Ethiopia. Biomedical Journal of Science and Technology Research 1(6):1-4.

Central Statistics Agency (CSA) (2011). Summary and Statistical Report of the 2010 Population and Housing Census: Population Size by Age and Sex. Available on: http://www.csa.gov.et/pdf/Cen2007_firstdraft.pdf, [Accessed on 23.09.09]

Derrick B, White $P$ (2017). Comparing two samples from an individual Likertquestion. International Journal of Mathematics and Statistics 18(3):1-13.

Dhaka BL, Meena BS, Suwalka RL (2010). Popularization of Improved Maize Production Technology through Frontline Demonstrations in South-eastern Rajasthan. Journal of Agricultural Sciences 1(.1):39-42.

Hiremath SM, Nagaraju MV (2009). Evaluation of front line demonstration trials on onion in Haveri district of Karnataka. Karnataka Journal of Agricultural Sciences 22(5):1093-1094.

Jeengar KL, Panwar P, Pareek OP (2006). Front line demonstration on maize in bhilwara district of Rajasthan. Current Agriculture 30:115116.

Lebeda A, Ryder EJ, Grube R, Dolezalov AI, Kristkov AE (2007) . Lettuce (Asteraceae; Lactuca spp.). In: SINGH R.J. (ed.), Genetic Resources, Chromosome Engineering and Crop Improvement, Vol. 3, Vegetable Crops. BocaRaton, CRC Press, Tailor and Francis Group, pp. 377-472.

Katare S, Pandey SK, MohdM (2011). Yield gap analysis of rapeseed mustard through front line demonstration. Agricultural Update 6:5-7.
Kiros G, Tesfya B, Tadesse A (2012). Participatory varietal selection of Lettuce variety (Lactuca sativa L.), unpublished Progress Report.

Kristkova E , Dolezalova I, Lebeda A, Vinter V, Novotna A (2008). 'Description of morphological characters of lettuce (Lactuca sativa L.) genetic resources', Horticultural Science (Prague) 35(3):113-129.

Kumar A, Kumar R, Yadav VPS, Kumar R (2010). Impact assessment of frontline demonstrations of Bajra in Haryana state. Indian Research Journal of Extension Education 10(1):105-108.

Mishra DK, Paliwal DK, Tailor RS, Deshwal AK (2009). Impact of frontline demonstrations on yield enhancement of potato. Indian Research Journal of Extension Education 9(3):26-28.

Mitra B, Samajdar T (2010). Yield gap analysis of rapeseed-mustard through front line demonstration. Agricultural Extention Review pp. 16-17.

Samui SK, Maitra S, Roy DK, Mandal AK, Saha D (2000). Evaluation on front line demonstration on groundnut. Journal of the Indian Society of Costal Agricultural Research 18(2):180-183.

Soto-Cerda BJ, Duguid S, Booker H, Rowland G, Diederichsen A, Cloutier $S$ (2014). Genomic regions underlying agronomic traits in linseed (Linum usitatissimum L.) as revealed by association mapping. Journal of Integrative Plant Biology 56(1):75-87.

Squire GR, Ong CK, Monteith JL (1987). Crop growth in semi-arid environment. In: Proceedings of 7th International Workshop, 7-11 April, 1986, International Crops Research Institute for Semi-Arid Tropics, Patancheru, Hyderabad, India pp. 219-231.

Tiwari BK, Aashutosh S, Sahare KV, Tripathi PN, Singh RR (2013). Yield gap analysis of wheat (Triticum aestivum) through front line demonstration under limited irrigation conditions. Plant Archives 14(1):495-498

Witcombe JR, Parr LB, Atlin GN (2002). Breeding rain fed rice for drought prone environment. Integrated convectional and participatory plant breeding in South and Southeast Asia. Proceedings of a DFID Plant Science Research Programme/IRRI Conference, 12-15 March 2002, IRRI, Los Baños, Laguna, Philippines. 